\title{
Positive Psychologists on Positive Psychology: Todd Kashdan
}

\author{
Interview by \\ Aaron Jarden
}

\begin{abstract}
Todd Kashdan, a.k.a. 'the guns of positive psychology', is an associate professor of psychology and senior scientist of the Center for Consciousness and Transformation at George Mason University. Todd trained in clinical psychology and is well known for his research into curiosity, social relationships, personality in daily life, meaning and purpose in life, and their links to all aspects of wellbeing.
\end{abstract}

\section{Are you curious about the questions I'm going to ask?}

Of course! I hate to know the questions ahead of time.

\section{Ok then, well, what prompted you to become interested in positive psychology?}

I've been in positive psychology a little over a decade now. The origin for me was when I was sitting in a doctor's office, and at the time I was studying anxiety and panic attacks. In the office was an issue of Psychology Today and the main article was about sexuality and high suicide rates, with a small subtitle referring to an article on happiness and flow (a concept I had never heard of before). Immediately I was thinking to myself that, while I'm devoting my career to helping people to deal with their anxiety problems, when it comes down to it, once their anxiety has dissipated, I'd basically shake their hand and say how amazing they'd been over the course of eight weeks and send them on their way; not thinking about or working with them on how they might organize their life now that they have eight extra hours of time and energy to devote to it. When I read [Mihaly] Csikszentmihalyi's article on happiness and flow I thought to myself, it's interesting, the idea that as psychologists, we're going to help people organize their lives, and that was the moment for me. I don't want just to reduce people's anxiety, in fact I don't know if that's always a good thing. I want to organize and structure people's lives in a way that's congruent with the values that they care most about. That all hit me when I was sitting in the doctor's office waiting for my dermatologist appointment.

\section{What did you do before positive psychology?}

Well before I did that I worked on the floor of the NY Stock Exchange as an assistant to a specialist. In brief, specialist firms create markets for particular stocks such that if there are lots of buyers but no sellers, they will step in and sell stock to particular people and companies. Essentially, for 30 stocks, any transaction in the world had to go through my fingertips.

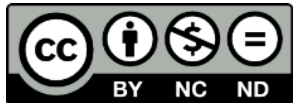

Copyright belongs to the author(s) www.internationaljournalofwellbeing.org 


\section{Were there any other key events that changed you and made you move into the field of positive psychology?}

My father left my twin brother and I when we were about two years old. My parents got divorced and then he just took off and never really spoke to us again. My mother died when I was thirteen. I never really defined myself as being someone who was an orphan or overcoming adversities, but everyone else always was surprised. I remember meeting a really distinguished psychologist at the University of Virginia, Irving Gottesman. He's well known for research on schizophrenia. After an interview with him he said to me, "You beat the odds, you're supposed to be in jail, you're supposed to be the drug addict, yet here you are, an orphan at 21 years of age, and you're just not supposed to be here at this stage of your life". It made me realize the power of resilience. You shouldn't be defining yourself by resilience, but it becomes embedded within the cells of your body. That's the type of idea that I like to promote in people's lives. Not to make it their aim to make themselves become resilient, but use what we know about the human condition to help them overcome difficult life events so that they get bred into the bone. This resonates with me because I've overcome loss and adversity, but never defined myself by that adversity.

\section{In general terms, and in your mind, what are some of the distinctive features of positive psychology?}

It's a tough question because there's the established foundation of positive psychology and then there's what I think it should be, and I always struggle between these two worlds. The core of positive psychology since its inception has been positive emotions and strengths of character; and then particular elements of relationships that allow them to flourish harmoniously for the long term. I think that all three of these are integral to living a well-lived life. I think that the problem is that positive emotions are the biggest strength and also the biggest problem for positive psychology. There are two ways of looking at positive emotions. One is that they are just a barometer or gauge that your life is going well. The other is that positive emotions are what we are aiming to construct-we want to construct our life so that there is a high frequency of positive emotions and a low frequency of negative emotions. To me, there are fundamental problems when this is the primary target for our interventions and what we want to create in our lives. I view positive emotions as the residual benefit of focusing on meaning and purpose in life, and close relationships. And from striving toward these personal projects, you're going to fill your pockets with emotional experiences. They're building blocks/cells and what's important is, 'What's the connective tissue among these moments?'. That is what should be more fundamental to positive psychology. What do you want to be written on your tombstone? What do you want to be in your obituary? I think few people are going to answer 'here lies a person who had a high frequency of positive emotions and a low frequency of negative emotions'. Instead, they are going to want a tombstone that discusses intimate relationships, self-sacrifice, the search for ultimate truths, accomplishment, etc. But I can understand why these deeper topics are not at the forefront of positive psychology. After all, they don't work as well in a media sound-bite. But we should be interested in the connective tissue among positive experiences and the architectural framework that houses them, as opposed to just increasing the amount of positive experiences. 


\section{What is one big question that positive psychology answers?}

How do you maintain a lasting, trusting, and satisfying relationship? Two people who want to be committed to each other in a way where each feels accepted, validated, understood, with a sense of vitality and room to continually evolve. I think we've nailed that.

Which professional groups of people are most interested in harnessing positive psychology? That's a really tough one!

\section{I mean positive psychology is being applied in education, in health, in organizations, in} therapy, even in the army. Is there somewhere else you think positive psychology is going to go next?

I hope that it is in the government. I think that right now education is where the action is. Everything should focus on the future. One of my big beefs with positive psychology is that there is insufficient generativity and generosity right now. There is an unusual culture of celebrities and hero worship: who's published the books, who are the distinguished professors, who's being cited in introductory psychology textbooks, who's making the money, those kinds of things. Who's the next generation? I don't know who the hell they are right now, but there are creative ideas floating around that people are afraid to reveal, given the possibility that they might look like idiots. Most people who come up with unusual great ideas, get rejected. I want to invest in the future of positive psychology. Right now education is where the action is. Everyone I talk to speaks about the idea that something is wrong at the government level in that they control resources, they decide how much money goes to improving the welfare of humanity, they decide how much money is going to the business organizations, they decide what products they are going to subsidize. With government at the highest realm of the hierarchy, that's where positive psychology needs to be playing a role. Right now there is almost nothing at the governmental level.

As a positive psychology practitioner and expert, are there any situations that you need to avoid, or things that you need to be careful of when you are applying the science in practice?

As a practitioner, here is the important question to attend to, 'What are the things the person, the couple, the organization that you are working with, are striving to obtain?'. Let's not impose outcomes on them. If they're interested in increasing courage and sharing creative ideas, and we end up being the world's greatest expert on morale and leadership, we have to start with and focus on the things they are interested in and not what we're interested in. What I worry about is that there are a lot of practitioners in positive psychology, but I don't know who is a generalist and who's a specialist. Ten years since the inception of this thing called positive psychology and there are still no specialties. You're just a positive psychologist. And I think that's particularly problematic. Should you be working with parents if the work you're most familiar with is Richard Davison's and pre-frontal cortex activity? If your primary knowledge base happens to be in positive organizational behavior, what exactly makes you qualified to work with parents and children and the interaction between them? 


\section{I know you're clinically trained and also do clinical work. Do you think the scientist- practitioner model that a lot of clinicians gravitate to is a good model for positive psychologists to adopt as well?}

The scientist-practitioner model has been a little problematic because of the requirement for everything to be empirically supported before it can be adopted in the world. The mantra that I have adopted over the past few years is that we should be guided, as opposed to governed, by the research. If that fits with the scientist-practitioner model, then I'm for it. However if the scientist-practitioner model sets the bar even higher before we can use the science, then I'm a bit unsure that this level of quality control can be sustained.

\section{I think I've heard you previously term this approach as being 'empirically informed'?}

Yes, scientifically informed. That's right.

\section{If you could start learning about positive psychology again from the beginning, I mean you're a decade or more in now, what would you do differently?}

Nearly everything that I have studied should be centered on the situational context that it is embedded in. That could be people in cults, it could be adults and their relationships with their friends or parents, it could be people embedded in their larger group cultural context. It doesn't have to be their country of origin, it could be the sub culture they identify with, such as hip-hop culture, Goth culture, the punk-rock culture. If I were to do it over again, I would have done two or three years focusing on understanding culture, understanding systems, understanding links between systems, and bringing that to my work with individuals and organizations.

\section{What are your plans for the future with regard to positive psychology?}

My big thing is friendships and romantic relationships. For me, this is the most important aspect of our lives. Cultivating these friendships after the age of 30 is complicated; I have no idea what I'm doing and I know many other people feel the same way. What worked as a child, teenager, and young adult, doesn't work as well in our 30s. When I was 20 years old, surrounded by other people in dormitories and bars, hanging naked from the rafters of a building somewhere, it was nearly impossible to avoid friendships. As you get older, it takes greater effort to find people and consistent effort to maintain friendships. To understand positive aging, we have to get a handle on life transitions. I'm not even referring to life at 65, 70, and 80; I'm talking about 30 to 35 years old. How do you cultivate new relationships when the characters around you have no understanding of the serpentine road it took you to get to where you are? How do you maintain action in a romantic relationship and honor the fact that you are still going to be attracted, seducing and being seduced by, other people in your life? How can you hold these different worlds simultaneously, with neither clashing? This is the realm that my work is going into, looking at people, looking at moments, all within a larger context.

\section{Who are the emerging and unknown positive psychology researchers to look out for?}

Good question. I think there are scientists in other fields of psychology that no one in positive psychology is talking about. Henk Aarts and Ap Dijksterhuis, in the Netherlands, study nonconscious processes, basically the idea that once you figure out your bike path to work, you get this mental module in your brain that you can access so quickly that you've got plenty of mental resources left over to focus on something else. For someone else who doesn't have a 
clear mindful way of getting to work, this is a resource intensive endeavor. What is powerful is the idea that we can shift mental resources to activities that are completely outside of conscious awareness so that we are better able to regulate the multitude of decisions, choices, and data that are flying towards us on a daily basis. Their work has great relevance to positive psychology, yet nobody is talking about this science much less how it can be applied when directly helping people.

\section{Anybody else?}

There's Jamie Goldenberg at the University of South Florida who's a Terror Management Theory researcher. What's interesting is that she applies this theory to sex and the notion that once you recognize the finality of existence and related existential issues, this affects how you treat your body in terms of dieting, in terms of sex, in terms of being attracted or repelled by the intimate sounds and smells of other people. It's the same notion that things outside of conscious awareness are constantly biasing and playing tricks on what we value and how we behave. And positive psychology is simply not paying adequate attention to unconscious processes. Completing self-report questionnaires won't cut it. Your answers when completing a self-report questionnaire are not necessarily going to converge with what you will actually do in a given situation where multiple options are available.

\section{What area of positive psychology do you still find difficult to understand? I mean, what's the real minefield for new players?}

Everything with non-linear dynamics is complicated.

\section{Can you be a bit more specific?}

Think about Barbara's Fredrickson's 3-to-1 ratio [of emotions]. It's based on the notion that human experiences and behavior are dynamic and non-linear. Think of the multitude of moments within a single day working in an organization. There are mathematical equations that can be calculated where, when there's an attraction, there are two attractors, one that attracts negative moments and one that attracts positive moments. Two attractors at the same time. It's as if a person's psyche has two vacuums. And there's the notion that if you have a particular ratio of positivity, you're more likely to be functioning optimally. I understand everything I just said, but the mathematics leading to that result is beyond my comprehension. How do I apply this knowledge to understand a person's ratio of mindful to mindless moments? How do these formulas help people use their finite currency of time and energy more wisely over the course of a single day? Given the notion that there are certain ratios, frequencies, and durations of experiences that lead to more successful outcomes, how can this be used to understand and improve people's lives? There appear to be mathematical formulas to tackle non-linear life trajectories, but I don't know how to calculate them, thus I can't ask the questions the way that I would like to.

\section{If someone wants to be happier, what's an individual's best bet for increasing their happiness and wellbeing?}

The data are clear that it's about appreciating the benefits you get from each moment as it unfolds. It's a combination of gratitude and mindfulness, which are two overlapping circles. Gratitude is the mindful recognition of benefits received, and mindfulness is a kind of open receptive attitude towards what happens as each moment unfolds. Put those two together, that 
attitude, that mind-set, that beacon of consciousness, and you can catch particular moments and make them linger both in the present as an increase in vitality and you can recall them at a later date as a mood boost. That's where the action is.

\section{In positive psychology you're renowned for research in the area of curiosity. Can you tell us a little bit about curiosity?}

Curiosity is one of the engines that make other elements in positive psychology work. You can't use your strengths in new ways without this process of clarifying strengths as well as the situations where they can be used most effectively. Where should I be changing my behaviors, my mind-set? When you reverse engineer this exploration of how to best use strengths, you're talking about turning curiosity inward towards the self. This runs counter to how people typically think of curiosity. We normally think of curiosity as a mindset turned outward to novel, uncertain, or challenging external stimuli-from people to situations. And the reason why curiosity, the curiosity field, has such lasting power is that most people don't think about how curiosity can be wielded like a laser, at any given point in time, and we can direct it outward or inward. We spend so much time trying to increase our positive mood that we forget periods of reflection and contemplation, and the importance of clarifying our values, about what's meaningful, about what we want, about what we want in 100 or so years on this planet to stand for. This mindset usually leads to a positive experience if we are willing to extract meaning, but the actual search itself, the emotional state, is pretty much inert, it's neutral. So there's a whole terrain of research and theory that is yet to be touched in terms of how you balance the external search for meaning and the external search for more positive moments as the building blocks for living a good life, versus using time for yourself to reflect on and synthesize how things are going and whether there is adequate movement in the direction of deeply valued life aims. Contemplation, introspection, curiosity turning inward, and this entire meaning making system is fertile terrain for the future of positive psychology.

\section{What's your one big hope for the future of positive psychology? Five years from now what would you like to see changed?}

Intellectually, I think we already have great scientists. We've got publications, we've got outlets, we're entering more territory than any other area of psychology ever has within a tenyear period. But what we don't have is those people who have that skeptical mind-set of, 'I'm not content with how things are and I want to continue building a future of new ideas, new theories, new ways to make things better', which sometimes means tearing things down and starting from scratch. Right now, the field of positive psychology is a bit too harmonious. Ironic in that this harmony serves as a strength and weakness. My hope is that in five years there will be an appreciation of rigorous challenges. Whatever is the ferment of the moment, whatever are the most exciting ideas, those will be challenged. Not by trying to win fame by tearing someone down, because we're all trying to build the greatest architectural masterpiece possible. Right now there is too much fear and mistrust about having ideas challenged by other people, about dealing with the ambiguity of where ideas work. Nearly all psychological ideas have their tipping points and boundary conditions, where the benefits no longer apply. We need to find them, and map this terrain. The ideas that are getting the most traction in positive psychology, strengths, positive emotions, gratitude, and mindfulness are being overemphasized. This is a common consequence of a paradigm shift. I think we have to appreciate questions such as 'When do these things not apply?', 'When are they not working?', 'When do they need to be scaffolded by another process?'. We need to examine constructs and 
interventions in tandem as opposed to separate, isolated ingredients. My hope is that innovative, integrative skeptics will represent the future of positive psychology, people thinking in greater complexity and people challenging people and ideas, and enjoying that challenge.

\section{What do you think is going to be the hot topic in the field over the next five years?}

It's already in psychology: regulatory processes outside of conscious awareness. This is already happening under the umbrella of social neuroscience. I think it's a nice way of describing the world! I'm not quite sure what you do with it in terms of improving the welfare of humanity. But recognizing that most of the things we do to enhance our lives occur outside of conscious awareness - that recognition alone can improve people's lives.

\section{Is there anything else you'd like to comment on that would be useful or interesting for someone looking at moving into the field of positive psychology?}

To be a good practitioner or scientist in this field you need to start with psychology, and then choose the topics that resonate within this lens of positive psychology. The idea of positive psychologists, of people specializing in positive psychology from the get-go, worries me because we have a hundred years of great ideas that could get lost quickly by attempting to start anew when a body of knowledge already exists. Let's build off the shoulders of predecessors.

\section{Author}

Aaron Jarden

Open Polytechnic of New Zealand

aaron.jarden@openpolytechnic.ac.nz 